\title{
Survey of the Relationship between Personality Types and Burnout among Teachers at First Period (Guidance School) and Second Period of High School (Secondary School) in the City of Rasht, Iran
}

\author{
Abbas Sadeghi' ${ }^{1}$, Nader Ofoghi², Gholam Hossein Niyafar ${ }^{3}$, Koorosh Dadashi ${ }^{3}$ \\ ${ }^{1}$ Department of Educational Sciences, University of Guilan, Rasht, Iran \\ ${ }^{2}$ Department of Social Sciences, University of Guilan, Rasht, Iran \\ ${ }^{3}$ Department of Psychology, University of Islamic Azad University of Rasht, Guilan, Iran \\ Email: asadeghi1394@gmail.com, n ofoghi@yahoo.com, niayfar.67@gmail.com, k.dadashy@gmail.com
}

Received 21 April 2015; accepted 25 May 2015; published 28 May 2015

Copyright (C) 2015 by authors and Scientific Research Publishing Inc.

This work is licensed under the Creative Commons Attribution International License (CC BY).

http://creativecommons.org/licenses/by/4.0/

(c) (i) Open Access

\section{Abstract}

This research investigated the relationship between John Holland's personality types (realist, investigative, conventional) with burnout among female and male teachers at first duration of high school (guidance school) and second duration of high school (secondary school). For this purpose, 327 persons were selected by multistage cluster sampling method. In order to gather information, Meshach burnout questionnaire and John Holland's job-personality questionnaire were used. Descriptive and inferential statistic methods were utilized to analyze the data. It was worth mentioning that Pearson correlation coefficient $r$, linear regression and the analysis of multivariable variance (MANOVA) were used to measure the relationship between predictor and criterion variables. Obtained results by the investigation of relations showed that there was a reversed relationship between personality types and the degree of burnout, with correlation coefficient of $r=$ $(-2.24)$, respectively, in the level of $(p=0 / 01)$. The relationship between realist, investigative and conventional personality types with burnout which was calculated by $(r=-1.15, r=-1.84, r=$ -2.19) respectively, was significant and reversed. It was necessary to say that among demographic variables (gender, age, precedent, education and teacher's marital status) there was just a significant relationship between gender, personality type and the degree of burnout in the level of $(p=$ $0 / 05$ ). It showed that from the view point of gender there was a significant difference between burnout. The degree of burnout in male teachers was more than female, and there were no significant differences in other demographic variables. The most important application of this study is that everybody will be employed according to his/her job-personality type to avoid any physical 
and mental damages arising from working.

Keywords

Personality Type, Burnout, Teachers

\section{Introduction}

Nowadays, because of technology improvement, human being needs and the ways of meeting of their needs have been changed and also the rate of evaluation has been made the human being to get adjusted quickly to these changes. But sometimes compatibility procedure won't happen for some reasons and results in stress. Because of importance and necessity of organizational life in working environment especially in professional areas which their staffs deal more with people or owner of service jobs, there is stress and it is remembered. Although all stress are not harmful, there is a useful stress as "professional stress" and that is existence of stress which is harmful for encouraging staff to work, and if with "professional burnout", the purpose of this research, harmful stress that is start of planning and adopted strategies of person or organization, won't be removed or reduced, and it results in "professional burnout" that follows high harms and costs for person and organization (Abbas Zadeh, 2008). Burnout is emotional exhaustion which is a result of continuous reaction task to chronic emotional and interpersonal stress triggers that are defined by the help of three aspects, emotional exhaustion, depersonalization and lack of success (sense of incompetence) (Maslach, 2003). Liod and Lesly's (2008) implied that burnout happens when that conducted task appears meaningless to person after a short time. Also, it can be a result of anxiety or variety in tasks related to person or personal factors. Today's society is the organizational community. Most of scientists believe that nature of today's society will be established and organized in different forms with different goals by organization, but undoubtedly all of them are managed and directed based on physical and mental attempts of manpower. Generally, it can be said that effective manpower is a major indicator of an organization excellence over other organizations. Existence of committed manpower to organization can cause considerable increase of organization performance, mental freshness of staff and better manifesting of noble objectives and also achieving to personal goals, in addition to reducing identity, delay and movement (Bahrami and et al, 2010). In recent years, burnout phenomenon has attracted the attention of many researches and productivity practitioners of manpower. The exact extent of burnout is not clear. However, it damages wide range of workforces and manpower (Guidance of world health organization, 1988). The main factor of burnout is mental stress tolerance which results from long work along with much work. Lack of interest in specialized work and profession that person works in it leads people to burnout (Farajpour, 2001).

The studies have shown that teaching is a stressful task and almost $1 / 4$ of teachers have stress during teaching. Also, other study has shown that high percentages of teachers (30 to 75 percents) have average and high stress in their work. Other study has shown that in western countries and east of Europe about 10 to 40 percentages of teachers have stress and burnout and that these percentages reach to 50 to 70 percent in countries like Iran, Japan and Taiwan (Frahani, 2011). The researches in the context of stress and teachers' depression have been started from 1970 decade. Statistics data show that the numbers of teachers who leave their job are increasing. Also, the research results show that the important reason why teachers leave their job is burnout. This is a big and tragic loss for financial investments and wasting academic talents.

Teachers are with different stress. One of the outcomes of these stresses is appearance of burnout among teachers. This burnout results from reaction related to stress, which leaves a lot of side effects in organization, in family and social and personal life. Among the most important of them are staff absence from work, successive delays, different psychiatric complaints, struggle and conflicts in workplace, change of teaching methods with other jobs and finally quit of the job. When burnout happens, there will be a lack of increasing realism, reduction of energy in continuing of useful activities, missing the last philosophy of life, lack of sympathy and mental and physical disorders. For overcoming these problems, we should deal with mental stress of burnout (LotfiNiya, 2010).

The conducted researches about burnout in teachers have shown that in the same working conditions, subjects won't equally suffer from burnout and in the other word; burnout comes from interaction of many factors such 
as personal, international, professional factors and personality traits (Shaufeli et al., 1994). In researches and theoretical models related to burnout, there has been much about importance of personality traits in dealing with this personal, organizational and social problem. The kind of personality types determines the mental abilities output and makes the describing of human behavior possible in life situations. Millon (1996) defines the personality in this way: "complex and very deep models of psychological characteristics that cannot be eradicated and almost it manifests itself automatically in all aspects of person performance. These characteristics are inherent and comprehensive and form complex matrix of biological preparations and learning and make perceptual model, feeling, thoughts and dealing methods of person”.

Many theoretical patterns have presented the theory about personality concept and have argued various classifications about personality types that one of the most important of them is in professional-personality context of John Holland's theory.

Holland is one of the major theorists in professional psychology context and his theory has been successful in attracting research activities than any other theory. Holland has based his theory on two principals:

1) Selecting job and profession depends on type of personality.

2) Selecting job and profession depends on individual's attitudes and trends.

John Holland's personality and professional theory that has recognized employees' typology in different professions and context has considerable importance and has proven its reliability in different studies (Holland, 1997). Holland emphasizes on importance of self-image in achieving to satisfaction and job stability. From Holland's point of view, self-image is: person's ability to identify potential talents in social context. Self-image is that knowledge and information which a person has about himself/herself. Holland knows the experience in childhood and way of nurturing in childhood and also its social pressures, important in determining preferences and personality type and self-image (Shafie Abadi, 2011). In short, it can be said that John Holland's theory and self-image and necessary job information emphasize on making decision and this theory has considerable impact on evaluating interests and professional methods (Zonker, 2009, translation of Yousefi and Abed).

Four main hypotheses form the heart of this theory. These hypotheses explain the nature of personality types and show that how types and models have been determined and how job, education and social phenomena will be created by their interaction (Brown and Snit, translation of Rezaei).

1) Individuals can be classified into one of the six types, realistic, spiritual, art, social, brave and conventional.

2) Environment can be classified into one of the six types, realism, investigative, art, social, brave and conventional.

3) Individuals are looking for an environment that can apply their skills and abilities.

4) Behavior will be determined by interaction between personality and environment.

Four above hypotheses are complemented with five secondary hypotheses (homology: distinction: prediction: consistency) that are true about individuals and environment. The purpose of hypotheses or secondary concepts is adjustment or determines predictions or descriptions that are derived from main concept.

Table 1 shows that with regard to presenting the theoretical models, various studies practically approve those different factors like personality types which are concerned with burnout phenomena.

\section{Table 1. Personality traits.}

\begin{tabular}{ll}
\hline \multicolumn{1}{c}{ Type } & \multicolumn{1}{c}{ Personality traits } \\
\hline Realist & $\begin{array}{l}\text { Unsociable, united, frank, original, strict, financial, normal, practical, self-centered, flexible, thrifty, } \\
\text { non-intuitive, unaffected }\end{array}$ \\
Investigative & $\begin{array}{l}\text { Analyzer, aware, complex, curious, independent, open-minded, introvert, careful, reasonable, reversed, } \\
\text { secluded, humble, unpopular }\end{array}$ \\
Art & $\begin{array}{l}\text { Ambigious, messy, emotional, extrovert, idealist, imaginative, impossible, self-motivated, independent, } \\
\text { introvert, intuitive, incompatible, creative }\end{array}$ \\
Sociable & $\begin{array}{l}\text { Self-confident, cooperative, patient, friend, generous, rescuer, idealist, empathic, kind, incentive, responsible, sociable } \\
\text { escuer, idealist, empathic, kind, incentive, responsible, sociablef-motivated, independent, introvert, intuitive, compatible॰ }\end{array}$ \\
Brave & $\begin{array}{l}\text { Excess demand, adventurer, courteous, ambitious, } \\
\text { domineering, energetic, blatant, thrill-seeking, extrovert, coquette, optimistic, self-confident } \\
\text { Conventional } \\
\text { Cautious, united, responsible, advocate, effective, inflexible, reversed, normative, obedient, tidy, active, practical, } \\
\text { forethoughtful, extrovert }\end{array}$ \\
\hline
\end{tabular}


Maslach and Jackson (1986) have concluded that role conflict and unfavorable partners can follow emotional burnout and result in depersonalization. In another research, Rocca and Kostonski (2001) didn’t find any relationship in surveying the degree of burnout and its relationship with employing of teachers, although male teachers experienced more burnout than female. Dorman (2003) found a meaningful relationship between class and school environment with depersonalization and relationship of self-esteem with burnout. Line and Goydn (1997) quoted from Yazdi that some people with special personality types were more prone to burnout. Research findings of Lotfiniya (2010) showed that among personality factors, extroversion, flexibility and conscientiousness have more effect on teacher's burnout. Regression analysis showed that conscientiousness has the most effect on burnout.

Montazer Gheib et al. (2012) showed that there is a meaningful relationship between Holland's personality type and burnout in this way that burnout is fewer in social type, and more in three types of realistic, conventional and bravery. Also there is no relationship between art type and burnout.

According to Arches (1991), sense of lack of autonomy and independence in work causes the burnout. O’Brien (2010) also conducted that there is a negative relationship between psychological empowerment and burnout but psychological empowerment cannot act as an independent predicator of burnout.

Whereas Ashrafi et al. (2010) in their research have concluded that there is a reverse relationship between organizational commitment and its aspect with burnout. Griffin et al. (2010) in their research have concluded that there is no relationship between organizational commitment and burnout.

ShakeraniNiya and Mohammad Poor (2010) in their research found that there is a positive meaningful relationship between job stress and nurses’ burnout. There is a negative meaningful relationship between job stress and nurses' burnout with their tolerance. Age, tolerance, stress factors and section of nurses working place could predict nurses' burnout. There is a meaningful difference between nurses' occupational groups from stress and burnout aspect. The difference between nurses who worked in heart and children section was not meaningful but this difference was meaningful in women and nurses who worked in emergency department. Kitchel (2012) in a research among agricultural teachers' job satisfaction and burnout from social aspect found that there is a meaningful relationship between emotional factors, depersonalization and personality performance of burnout with degree of job satisfaction that the higher job satisfaction is, the lower burnout and stress are. Also, Ferari (2010) in a study investigated job stress and burnout in teachers. Their research results showed that there was a meaningful difference between job stress in female and male teachers. But female teachers experienced more burnout than male teachers. Niyerl et al. (2009) found that based on surveying working pressure, burnout and job satisfaction, they had concluded that there is a positive and meaningful relationship between shifts and working hours per week and working pressure and burnout and also it was found that there was a negative relationship between public service in comparison with physicians' private job and age with working pressure and burnout and having much responsibilities and increased working hours caused imposing high working pressure to physicians with various specialties and increased burnout. Farmer (2009) in a research about relationship between emotional intelligence with burnout and teachers' job satisfaction has concluded that generally there is a relationship between emotional intelligence with job improvement. Skaalvik and Shalvik (2010) in investigating the relationship between self-efficacy and Norwegian teachers' burnout found a meaningful relationship between teachers’ personality and individuality aspect with degree of depression.

Salma et al. (2009) showed that tendency performance in teachers is predicator of high level of work commitment and low level of depression. In contrast, a high level of avoidance performance in educating periods was predicator of low level of work commitment and high level of depression in later job periods. Edward et al. (2007) conducted a research about tolerance behaviors and burnout in teachers which concluded that teachers, who benefited from behaviors and tolerance capacities in dealing with professional problems for staying healthy, suffered less from burnout. Hakanen et al. (2006) found that there is a positive relationship between burnout and its relevant diseases and negative relationship between participation and organizational commitment and burnout. Fujiwara et al. (2003) in a study about investigating the relationship between burnout with teachers' coping methods found that there is a positive and meaningful correlation between interpersonal conflicts with depersonalization and emotional exhaustion. Also, burnout correlation of teacher's social support from staff in different jobs has been approved in various researches. Merima, Zavavi, Hitam and Judi (2011) showed that burnout has considerable effect especially on "emotional commitment”. RezaeeShirazi et al. (2011) showed that there is a negative and meaningful relationship between burnout and organizational commitment, and organizational commitment especially emotional commitment is high in official teachers than other teachers. 
Burnout has negative effect on self-efficacy procedures and positive performance and teachers' relationship and this effect is also observable on educational procedures. As it is said, several internal and external factors are underlying of job stress and one of the most important of them is not the same as person's personality type with the job he chooses. As the kind of subject's personality type shows the kind of dealing a person with different situations, these types should be accounted especially as professional and educational guide (Montazer Gheib, 2012). Considering the theoretical background and above materials, the general purpose of this research is investigating the relationship between personality type as a whole, and classification of realist, investigative and John Holland's types with types of teacher depression at guidance school and high school of Rasht.

\section{Research Main Hypotheses}

1) The first main hypothesis: there is a relationship between personality type and teachers burn out.

\subsection{The Sub Hypotheses}

1) There is a relationship between realist personality type and teachers burnout.

2) There is s relationship between investigative personality type and teachers burnout.

3) There is a relationship between formal personality type and teachers burnout.

\subsection{The Main Research Question}

1) Is there any relationship between personality type and burnout with regard to teacher's gender from relation aspect?

2) Is there any relationship between personality type and burnout with regard to teachers' age from relation aspect?

3) Is there any relationship between personality type and burnout with regard to teachers' background from relation aspect?

4) Is there any relationship between personality type and burnout with regard to teachers' education from relation aspect?

5) Is there any relationship between personality type and burnout with regard to teachers' marital status from relation aspect?

\section{Research Methodology}

This research is a kind of correlation that in this method, personality traits and (dependent) criterion variable of burnout will be predicted from (independent) predictor variable and method of gathering information is field type. Statistic society of this research is all male and female teachers in guidance and high school of Rasht in sectors 1, 2 that their total number is 2255 persons. Among employed teachers in guidance school and high school of Rasht in sector 1, 2, 327 persons were selected using Morgan table through multistage cluster sampling method. In this research two methods have been used, descriptive statistics include tables and graphs and descriptive statistics parameters like central and dispersion parameter and inferential statistics have been used for evaluating the relationship between predictor variable and criterion from Pearson correlation coefficient (r), linear Regression and the analysis of multivariable variance (MANOVA).

\section{Instruments}

In this research two John Holland's job-personality and Maslach’s burnout questionnaire has been used:

a) One of used means in this research is John Holland's job-personality questionnaires (1971). This test has been written by John Holland and based on his job-personality theory that classifies subjects and professional environments into 6 types or models of realists, investigative, conventional, social, brave and art. This questionnaire has 45 phrases that subjects in terms of their conditions mark each of phrases that they see in themselves and the highest score which a person gets toward answering each items of test will get the regarded kind of personality type. There are 15 separate phrases and dedicated to the same personality type for each of personality type of realist, investigative and conventional.

Validity: Increasing and comprehensive application of this means in job-personality and also educational as- 
pect shows its high validity and it's necessary to say that above questionnaire for using in this research is approved by 3 professors of Psychology Faculty.

Reliability: For achieving reliability, this questionnaire was conducted on 45 subjects from 9 occupational groups. The obtained amount of reliability was accounted by Cronbach Alpha and indicator of questions standardization was equal to 88\% (MontazerGheib \& Kikhanzhad, 2012).

b) Another means for evaluating burnout is Maslach's burnout questionnaire (2001). This questionnaire has 23 questions which studies four factors of emotional exhaustion, personality performance, depersonalization and conflict, separately. Scoring of this test is conducted in 5 items Likert criterion as completely agrees, agrees no idea, disagrees and completely disagrees and subjects burnout scoring is obtained from total scores. The questions $(1,2,3,8,13,14,16$, and 20$)$ are related to sub-criterion of emotional burnout. The questions (5, 10, 11, $15,22)$ are related to subscales of depersonalization and also questions $(4,7,9,12,17,18,19,21)$ are related to subscales of lack of personal achievement. Rating of this items are as follow that 1 score is given to completely agree, 2 scores to agree, 3 scores to no idea, 4 scores to disagree and 5 scores to completely disagree. Of course questions $(1,2,3,5,6,8,10,11,13,15,16,20,22)$ of this questionnaire are accounted for rating as reverse and questions $(4,7,9,12,17,18,19,21)$ are accounted directly. The minimum grade of this test is 22 and maximum grade is 10. Question number 23 evaluates the burnout as a whole.

Maslach and Jackson (1981) considered the reliability of three main test subtests between $72 \%$ to $89 \%$ for the burnout questionnaire. For the first time, Authority and reliability of Maslach's burnout questionnaire was approved by Philiyan in Iran. That its reliability coefficient has been reported (Alfa $=0.78$ ) through test of retest method.

Shofly and colleagues have reported the internal stability of this questionnaire 0.71 to 0.91 by Cronbach Alpha coefficient and its retest coefficient between 0.60 to 0.80. MontazerGheib and Kikhanzhad (2012) have determined the amount of calculated Cronbach Alpha 89\%for emotional analysis, personal performance 69\%, depersonalization 51\% and conflict 56\%. Additionally in this research, questionnaire Cronbach Alpha in a pilot project on a sample of 30 persons similar to the original sample, is 0.91 .

\section{Findings}

The main hypothesis: There is a relationship between personality types and teachers burnout.

Table 2 shows that there is a reverse relationship between personality type and their degree of burnout. That is, with increasing grade in personality types, teachers' burnout will decrease.

Table 3 shows that there is a meaningful and reverse relationship between three variables of realists, investigative and conventional and the degree of teacher burnout.

\section{Hypotheses regression results:}

Table 4 shows that, because in 3 entered predictor variables in regression equation just conventional personality type remains, it can lonely determine about $5 \%$ percentage of changes in criterion variable, that is, burnout.

Table 5 shows that regression equation is a linear equation. That is criterion variable is predictable.

Table 6 shows the lonely process 22\% percentage of degree of burnout. In the other words, with increasing 1

Table 2. The main hypothesis.

\begin{tabular}{lcc}
\hline & Burnout & Personality type \\
\hline Pearson correlation coefficient & 1 & $*-0.224$ \\
Meaningful level of burnout & & 000 \\
Number & 319 & 319 \\
Pearson correlation coefficient & $*-0.224$ & 1 \\
Meaningful level of personality type & 000 & 319 \\
Number & 319 & \\
\hline
\end{tabular}

“Pearson correlation coefficient in level 0.01 ”. 
Table 3. Subhypotheses.

\begin{tabular}{|c|c|c|c|c|}
\hline Hypothesis & Meaningful level & Pearson correlation coefficient & $\mathrm{N}$ & $P$ \\
\hline $\begin{array}{l}\text { There is a relationship between realist and } \\
\text { teachers burnout personality type }\end{array}$ & 0.020 & -0.115 & 319 & $P=0.05$ \\
\hline $\begin{array}{l}\text { There is a relationship between investigative and } \\
\text { teachers burnout personality type }\end{array}$ & 000 & -0.184 & 319 & $\mathrm{P}=0.01$ \\
\hline $\begin{array}{l}\text { There is a relationship between conventional and } \\
\text { teachers burnout personality type }\end{array}$ & 000 & -0.219 & 319 & $P=0.01$ \\
\hline
\end{tabular}

Table 4. Multiple regression.

\begin{tabular}{cccc}
\hline Model & $\begin{array}{c}\text { Multiple correlation } \\
\text { coefficient }\end{array}$ & $\begin{array}{c}\text { Determination } \\
\text { coefficient }\end{array}$ & $\begin{array}{c}\text { Revised determination } \\
\text { coefficient }\end{array}$ \\
\hline 1 & 219 & 0.48 & 0.45 \\
\hline
\end{tabular}

Table 5. Analysis of multiple regression variances.

\begin{tabular}{cccccc}
\hline Model & Sum of squares & df & Mean squares & F(Fisher) & Meaningful level \\
\hline Regression & 2450.943 & 1 & 2450.943 & 15.900 & 000 \\
Remained & 48865.834 & 317 & 154.151 & & \\
Total & 51316.777 & 318 & & & \\
\hline
\end{tabular}

Table 6. Regression coefficient.

\begin{tabular}{|c|c|c|c|c|c|}
\hline \multirow{4}{*}{ Conventional } & \multicolumn{2}{|c|}{ Non-standard coefficient } & \multirow{2}{*}{$\begin{array}{c}\text { Standard coefficient } \\
\text { Beta }\end{array}$} & \multirow{2}{*}{ Calculated t } & \multirow{2}{*}{ Meaningful level } \\
\hline & $\mathrm{B}$ & Standard error & & & \\
\hline & 52.673 & 2.248 & \multirow{2}{*}{ 2.19- } & 23.436 & 000 \\
\hline & 868-. & 218. & & 3.987 & 000 \\
\hline
\end{tabular}

unit of standard deviation in conventional personality type, the degree of burnout will be increased about $22 \%$ units of standard deviation.

As it was noted earlier, the main question of research is looking for the relationship between personality types with demographics variables that description indicators and various levels of variables are as follow:

Table 7 shows the Mean and Standard deviation of the demographic variables of the research.

Table 8 shows that there is a meaningful difference between linear mixture of two variables of personality type, burnout and between employed female and male (teachers). In the other words, according to the obtained mean scores from teacher burnout criterion in Table 7 descriptive indicators of questions, male teachers have higher burnout than female teachers. It's necessary to say that in other demographics variables based on Landie Vilex test result, a meaningful difference in their relevant different groups that was noted in descriptive indicators table of research question (number 7), was not obtained.

\section{Discussion and Conclusion}

The main hypothesis: there is a relationship between personality type and teachers' burnout. This relationship is a reverse relationship between personality type and burnout. That is, when the subjects' score in personality types is high, it seems that their burnout will decrease. Subjects' personality type is a framework for their way of life and proportionally plays effective and important role in dealing with different factors. This dealing is observable in all level of life, especially professional life. The first damage that comes from burnout will be upon the person himself; while the most important means that person can apply for dealing with effects from burnout is a personality and inner trait of that person. Thus, we can argue that the relationship between subjects' personality type and burnout cannot be meaningless. 
Table 7. Descriptive indicators of questions.

\begin{tabular}{|c|c|c|c|c|c|c|}
\hline & & Mean burnout & Mean personality type & $\begin{array}{c}\text { Standard deviation } \\
\text { of burnout }\end{array}$ & $\begin{array}{l}\text { Standard deviation } \\
\text { of personality type }\end{array}$ & Total \\
\hline \multirow{2}{*}{ Gender } & Female & 40.385 & 11.6213 & 11.3347 & 2.75532 & 169 \\
\hline & Male & 48.393 & 11.2133 & 12.8585 & 2.40753 & 150 \\
\hline \multirow{3}{*}{ Age } & Under 30 years & 49.042 & 11.453 & 14.3935 & 2.24537 & 24 \\
\hline & Between 30 - 40 years & 43.794 & 11.4046 & 11.9136 & 2.57437 & 131 \\
\hline & Between 41 - 50 years & 43.720 & 11.4451 & 12.9840 & 2.64518 & 164 \\
\hline \multirow{3}{*}{ Precedent } & Under 10 years & 45.405 & 11.4048 & 12.9428 & 2.3065 & 42 \\
\hline & Between 10 - 20 years & 43.569 & 11.3761 & 12.2704 & 2.43352 & 109 \\
\hline & Upper 21 year & 44.214 & 11.4702 & 12.9680 & 2.74664 & 168 \\
\hline \multirow{4}{*}{ Education } & Diploma & 44.091 & 10.9091 & 10.2349 & 2.15824 & 22 \\
\hline & B.A & 43.795 & 11.4955 & 12.6876 & 2.60750 & 220 \\
\hline & M.A & 45.013 & 11.7933 & 13.5202 & 2.58045 & 75 \\
\hline & P.H.D & 51.500 & 7.5000 & 12.208 & 7.0711 & 2 \\
\hline \multirow{2}{*}{ Marital status } & Single & 47.593 & 11.4074 & 14.9878 & 2.46918 & 27 \\
\hline & Married & 43.832 & 11.4315 & 12.4529 & 2.59520 & 292 \\
\hline
\end{tabular}

Table 8. Multivariable variance test question of research.

\begin{tabular}{cccccc}
\hline Landie Vilex test & Gender & Age & Precedent & Education & Marital status \\
\hline Value & .875 & .974 & .991 & .971 & .989 \\
Degree of freedom & 3.000 & 6.000 & 6.000 & 9.000 & 3.00 \\
Meaningful level & 000 & .219 & .842 & .422 & .329 \\
\hline
\end{tabular}

The results of research hypothesis are indirectly consistent with researches of Nasrollahi et al. (2013), Khaghani Zadeh (2012), Montazer Gheib, Sheikhy (2012), Lotfiniya (2012), Shafie Abadi (2006). They found that there is a meaningful relationship between kind of personality type and the degree of subjects' burnout that in some researches this relationship is direct and in some other is reverse, for example Lotfiniya (2010) in his research argued that there is a reverse relationship between teachers' personality traits and their burnout especially those who are more extrovert and more flexible, their burnout will be decreased.

The first hypothesis: "There is a relationship between realist personality type and burnout."

Statistic results showed that with $95 \%$ percentage of confidence we can say that there is a reverse relationship between realist personality type and burnout. Realist individuals show characteristics such as obstinacy, persistency and practicality. It's normal that these subjects with reinforcing and existence of such features not to have a good relationship with burnout. Because of these characteristics, tolerance and obstinacy toward unfavorable events is high in these subjects and realist subjects with such characteristics have minimum burnout from work.

Obtained result from processing of this hypothesis based on existing a relationship between characteristics such as obstinacy, accuracy and self-image with degree of burnout is consistent with research of Yazdi Doost (2012), Narimani and Abbasi (2009), Tugade, Fredrickson (2004), Amini (2013) Inier Shelvik (2009). This hypothesis result is inconsistent with Montazer Gheib’s findings (2012). He found that among John Holland's personality types, 3 types of realists, conventional and bravery have the most direct relationship with teachers' degree of burnout.

The second sub hypothesis: “There is a relationship between investigative personality type and teachers' burnout. 
Statistics analysis result shows that with $99 \%$ percentage of confidence, there is a reverse relationship between investigative personality type and degree of burnout. That is, with increasing the score of investigative personality type, their burnout will decrease. These subjects enjoy from scientific activities that conduct studies in it in order to test new ideas or increase products. In some way they can be considered introvert and also are creative and since show their interest in doing their favorite activities or by using personality traits which mentioned above, it's clear that their burnout will be minimum. And this research is indirectly consistent with research of LotfiNiya (2010), Abdollahi (2006), GhorbanShiroodi (2006), Martine (2009), for example GhorbanShiroodi (2006), obtained a meaningful and reverse relationship between introversion, creativity and curiosity personality traits and burnout.

The third hypothesis: "There is a meaningful relationship between conventional personality type and teachers' burnout."

Statistics results show that with $\mathbf{9 9 \%}$ percentage of confidence we can say that there is a reverse relationship between conventional personality type and their degree of burnout. Work commitment and discipline and almost extroversion are conventional subjects' traits. These individuals can control themselves very well and it's clear that subjects especially teachers who have above personality traits can control themselves in occupational stress situations and by reinforcing personal traits can reduce the degree of burnout which they may encounter because of inconsistency with its professional conditions. Hakanen et al. (2006) found that there is a reverse relationship between work commitment and burnout which this result is indirectly consistent with above result. As realist individuals more like to type B, act bloodedly and thoughtfully, research result of Nasrollahi et al. (2013) is considered consistent with this result which increasing the score of type $\mathbf{B}$ has reverse relationship with degree of burnout. Research result of Fontana (1992), Ahangar (2006), Neberger (1979) and BeigiFard (1999) that considered extroversion and discipline of teachers' work commitment, has also consistent result with this research result. Research findings of MontazerGheib and Kikhanzhad (2012) are consistent with third sub hypothesis. He found this result that among John Holland's personality type; three types of realist, conventional and bravery have the most direct relationship with teachers' degree of burnout.

This research has limitations that causes it will be generalized with caution that is: for getting information we had to use questionnaire, teachers' lack of cooperation and lack of interest was seen in teachers because previous research results were not reflected on them. In the process of formulating research and gathering information, lack of time was felt as a limitation.

Useful points that we can get from this research, with regard to relationship of personality traits with teachers' burnout; it's necessary that education authorities attention to general and specific conditions of regulations and their personality traits in choosing teachers. Realist, investigative and conventional types from unique features aspect which show in dealing with stressful and burnout events, show a good resistance toward burnout and don't easily influence on themselves and their performance by this problem. Thus, for positions like teaching that degree of burnout in this job has been high in extensive researches it's suggested that because of existing reverse relationship with degree of burnout in these important jobs of society, to get benefit from this personality type.

\section{References}

Abbas Zadeh, M. (2008). Investigating the Relationship between Leading Styles of Managers and High Schools’ Burnout of Uremia in Educational Year of 85-86.

Abdollahi, M. R. (2006). Relationship between Job Stressors and Educational Managers Fars Arshdgrvh Management. Thesis, University of Shiraz, Shiraz.

Ahangar, A. (2006). Evaluation of Burnout and Its Relationship to Personality Types Tehran Consultants. Psychology Msc Thesis, University of AllamehTabatabai, Tehran.

Arches, J. (1991). Social Structure, Burnout, and Job Satisfaction. Social Work, 36, 202-206.

Ashrafi, et al. (2010) Investigated the Relationship Burnout and Organizational Commitment of School Teachers in Schools in the City of Mahabad. Journal of Psychology, University of Tabriz, 18, 5.

Bahrami, et al. (2010). Comparative Study of Organizational Commitment Based on Personal Characteristics. Journal of School Health, Yazd, No. II and III.

BeigiFard, S, (1999). Investigate the Relationship between Personality Hardiness and Social Support and Burnout Occupational Rehabilitation Centers Shiraz Welfare, MS Thesis Psychology Public Welfare and Rehabilitation Sciences. 
Dorman, J. (2003). Testing a Model for Teacher Burnout. Australian Journal of Educational \& Developmental Psychology, 3, 35-47.

Skaalvik, E. M., \& Skaalvik, S. (2010). Teacher Self-Efficacy And Teacher Burnout: A Study of Relations. Teaching and Teacher Education, 26, 1059-1069. http://dx.doi.org/10.1016/j.tate.2009.11.001

Edward, K. L., \& Herselinsky, J. G. (2007). Burnout in the Caring Nurse: Learning Resilient Behaviors. British Journal of Nursing, 16, 240-242. http://dx.doi.org/10.12968/bjon.2007.16.4.22987

Farajpour, A. (2001). Burnout. Burnout Magazine Saf, No. 259

Farmer, R. N. (2009). Measurement of Job and Work Involvement. Journal of Applied Psychology, 32, 135-144.

Ferrari Occhionero, J. W. (2010). Factors That Influence Nurses’ Job Satisfaction. Journal of Nursing Administration, 33, 293-299.

Fontana, D., \& Abouserie, R. (1992). Stress Levels, Gender and Personality Factors in Teachers. British Journal of Educational Psychology, 63, 261-270.

Frahani, M. (2011). The Relationship between Personality and Job Burnout of Physical Educators in Znjan.pzhvhsh Motor Sport Management Sciences. First Year-1.

GhorbanShiruodi (2006). The Relationship between the Type of Personality, Locus of Control and Job Satisfaction and Burnout among Staff Iran Khodro, Knowledge and Research in Psychology. University of Isfahan, No. 27.

Griffin, M. L., Hogan, N. L., Lambert, E. G., Tucker-Gail, K. A., \& Baker, D. N. (2010). Job Involvement, Job Stress, Job Satisfaction, and Organizational Commitment and the Burnout of Correctional Staff. Criminal Justice and Behavior, 37, 239-255. http://dx.doi.org/10.1177/0093854809351682

Holland, J. L. (1997) What Is Your Suitable Job? Translation of Simin Hosen Niyan and MonavarYazdi, Tehran, Physical Perfection, AEGON Print, Page 26.

Hakanen, J. J., Bakker, A. B., \& Schaufeli, W. B. (2006). Burnout and Work Engagement among Teachers. Journal of School Psychology, 43, 495-513. http://dx.doi.org/10.1016/i.jsp.2005.11.001

Khaghani, Z. (2012) Examined the Relationship between Job Stress and Quality of Work Life Teachers. Journal of Military Medicine.

Kitchel, T. (2012). Teacher Job Satisfaction and Burnout Viewed through Social Comparisons. Journal of Agricultural Education, 53, 31-44.

LotfiNiya, H. (2010). Investigating the Relationship between Personality Traits with Elementary Teachers’ Burnout in Tabriz, Physical Science, Third Yearmnumber11, 93-106.

Martine, E. (2009). An Organizational Culture Model to Promote Creativity and Innovation. Journal of Industrial Psychology, 28, 58-65.

Maslach, C., \& Jackson, S. E. (1986). Burnout Research in the Social Services: A Critique. Journal of Social Service Research, 10, 95-105. http://dx.doi.org/10.1300/J079v10n01_09

Maslach, C. (2003). Job Burnout: New Directions in Research and Intervention. Current Directions in Psychological Science, 12, 189-192. http://dx.doi.org/10.1111/1467-8721.01258

Merima, N. H. B., Zawawi, N., Hitam, M., \& Jody, J. M. (2011). Organizational Commitment and Job Burnout among Employees in Malaysia. IACSIT Press, 1, 185-187.

Millon, T. (1990). Toward a New Personality. New York: Wiley, 3.

MontazerGheib, T., \& Kikhanzhad, M. (2012). The Relationship between Burnout Factors and John Holland's Personality Type among Teachers and Managers of Elementary Schools. Journal of Job and Organizational Consultation.

Narimani, M., \& Abbasi, M. (2009). Investigating the Relationship between Psychological Hardiness and Self-Tolerance with Burnout. Second Year Management, Number 8.

Nasrollahi, A. et al. (2013). Investigated the Relationship between Burnout and Personality Types (A and B) and Job Satisfaction among Teachers of Kindergartens City of Ilam. Ilam University of Medical Sciences Journal.

Neberger, F. (1979). The Staff Burnout Syndrome in Alternative Institutions. Psychotherapy, Theory, Research and Practice, 12, 73-82.

Niyerl, J. et al. (2009). A Test of Gender and Job Models of Sex Differences in Job Involvement. Social Forces, 66, $121-142$.

O’Brien, J. L. (2010). Structural Empowerment, Psychological Empowerment and Burnout in Registered Staff Nurses Working in Outpatient Dialysis Centers. Unpublished Doctoral Dissertation, Newark, NJ: Rutgers the State University of New Jersey-Newark.

RezaeeShirazi, R., Beiki, Y., Zmanian, F., \& Esapour, K. (2011). Study of the Relationship between Organizational Commitment and Job Burnout among Physical Education Teachers of Golestan Province, Iran. Australian Journal of Basic and 
Applied Sciences, 5, 1379-1384.

Rocca, A. D., \& Kostonski, M. (2001). Burnout and Job Satisfaction among Victorian Secondary School Teachers. A Comparative Look at Contract and Department Employment Discussion Paper ATEL Conferences, 24-26.

Salma, A. K., Savolainen, H., \& Holopainen, L. (2009). Depressive Symptoms and School Burnout during Adolescence. Journal of Youth and Adolescence, 6, 34-45.

Shafie Abadi, A. (2011). Career and Professional Guidance and Consultation and Ideas of Choosing Job. Ministry of Culture and Islamic Guidance.

ShakeraniNiya, I., \& Mohammad Poor, M. (2010). Relationship between Job Stress and Tolerance with Burnout in Female Nurses. Scientific Journal of Research.

Shaufeli, W. B., Maslach, C., \& Mark, T. (1994). Professional Burnout: Recent Development in Theory and Research. Washington DC: Taylor and Francis, 201-211.

Tugade, M. M., \& Fredrickson, B. L. (2004). Resilient Individuals Use Positive Emotions to Bounce Back from Negative Emotional Experiences. Journal of Personality and Social Psychology, 86, 320-333. http://dx.doi.org/10.1037/0022-3514.86.2.320

Zonker, V. (2009). Consulting Career with a Holistic Approach. Translators: Yousefi and Abedi, Unit of Esfahan. 